
\title{
R Research S Suare \\ Clinical profile and visual outcome of complicated cataracts in eye care center in western central India
}

MEHUL SHAH ( $\nabla$ omtrustdahod@gmail.com )

Drashti Netralaya

Shreya Shah

Drashti Netralaya

Apeksha Kataria

Drashti Netralaya

Ashvini Korane

Drashti Netralaya

Mrugesha Vaghela

Drashti Netralaya

\section{Research Article}

Keywords: Complicated cataract,post uveitic cataract,traumatic cataract,cataract with corneal opacity

Posted Date: February 14th, 2022

DOI: https://doi.org/10.21203/rs.3.rs-1356526/v1

License: (c) (1) This work is licensed under a Creative Commons Attribution 4.0 International License. Read Full License 


\section{Abstract}

Introduction: Complicated cataract having poor prognosis, because of comorbidities. We tried to study visual outcomes in all clinical conditions.

Methods: This is prospective cohort study to develop scoring system to predict visual outcome in case of complicated cataracts. We enrolled all complicated cataracts fulfilling inclusion criteria between august 2019 to 2020.For All enrolled cases data collected in pre tested online format in Electronic medical records. All data exported and analysed with SPSS 22 using descriptive, cross tabulation and One sample T test functions.

Results: Our cohort was consisted of 230 eyes of 230 patients with mean age 44+/-21.22 years with $121 / 230(52.6 \%)$ female and 109/230(47.4\%) male.

Traumatic cataracts (64/230) Cataract with Corneal opacity (45/230) Post uveitic cataract (43/230) Neglected cataract (39/230). We had 37/230 (16.1\%) pediatric population with significant poor outcome. We found significant difference in pre and post-operative visual outcome.

Conclusion: Complicated cataracts with different co morbidities has significant improvement in visual outcome following comprehensive management. Neglected cataracts has better outcome than other categories.

\section{Introduction}

Cataract blindness Cataracts are responsible for $47 \%$ of all cases of blindness worldwide. The epidemiological impacts of cataracts are not the same in different countries, and the rates are associated with the prevailing economic conditions. In developed countries with good healthcare, cataracts account for only $5 \%$ of the cases of blindness, whereas the issue is still responsible for $50 \%$ of such cases in the developing countries. After a brief overview of the historical, clinical, and therapeutic aspects, this article presents an update on the global epidemiological cataract data. It also provides insights into the political, socioeconomic, and cultural factors that adversely affect the availability of healthcare in developing countries, making cataract a major public health concern and an impediment to development. ${ }^{[1]}$

The prevalence of cataracts increases with age. As the world's population ages, the incidence of cataractinduced visual dysfunction and blindness is rising, which represents a significant global problem. The challenges include preventing or delaying the formation of cataracts and treating those that occur. ${ }^{[1]}$

Cataracts can be cured by surgery, however, this option is not equally available everywhere and all surgical methods do not produce similar outcomes. Standard surgical services capable of providing good visual rehabilitation must be made accessible to all in need, regardless of their circumstances. The establishment and sustained delivery of these services requires comprehensive strategies that go beyond a narrow focus on surgical techniques. Changes in governmental priorities, population education, and an 
integrated approach to surgical and management training are warranted. ${ }^{[2]}$ India is a signatory to the World Health Organization Resolution on Vision 2020. The concerted efforts of all the stakeholders have resulted in a hike in the number of cataract surgeries performed in the country. However, the actual impact of these measures on the elimination of avoidable blindness is unknown. ${ }^{[3]}$

Visual outcome of cataract various risk factors impact the outcome of cataract surgery. Each of these risk factors increases the possibility of an adverse outcome during cataract surgery. However, until recently, prediction of the likelihood of a complication during phacoemulsification surgery has been based on a subjective assessment of the patient by the surgeon. Various studies have identified individual risk factors that increase the risk of intraoperative complications. [1-5]

There are complicated cataracts secondary to or coexisting with other ocular conditions may not have similar outcome as uncomplicated primary cataracts.

As these are many conditions which may have different outcomes

Objective is to prognosticate complicated cataracts because of different causes

So outcome may be variable Visual outcome according to various categories of complicated cataracts studied.

1. Post uveitis cataracts

2. Traumatic cataracts

3. Cataracts in association with colobomas

4. Cataracts following glaucoma surgeries and

5. Cataracts following Glaucoma/vitreo retinal surgeries

6. Cataracts with corneal opacities

7. Cataract with poor zonular support

8. Other type of complicated cataracts

\section{Materials And Methods}

This is a prospective, hospital-based study conducted in XXX after ethical clearance from XX hospital ethical committee .patients presented as complicated cataracts during august 2020 and august 2021 were enrolled.

Detailed history taking, visual acuity slit lamp bimicroscopic examination

Cycloplegics refraction was performed and fundus examination with binocular Posterior segment examination done using Indirect ophthalmoscope. B scan was performed in case of opaque media oct done whenever possible according media clarity 
Digital biometric reading was done according to clinical conditions and specific power calculation formulas used post refractive surgery or post vitrectomy and eyes with silicon oil. For eyes with corneal opacity keratometry of other eye was taken in account. Surgical management was done according to clinical conditions.

For uveitic cataract management Control of inflammation using periocular or systemic steroids followed by surgery Clinical findings were considered for surgical techniques. Occlusion pupillae, where membrane was removed, synecheolysis using Ocular Viscoelastic Devices micro forceps was used to grasp the pupil edge to initiate pupil edge membrane peeling. Stripping of the fibrotic tissue band around the pupil margin allowed immediate dilation of the pupil. Proper Post operative care to control uveal inflammation For traumatic cataract management: Traumatic cataracts mainly were classified according to their morphology and mechanism of injury.(7) All open globe injuries causing traumatic cataract operated using second sitting. Traumatic cataracts removed either using aspiration, delivery or phaco emulsification along with primary posterior capsulotomy and vitrectomy. (8) For all ectopia lentis cases After careful evaluation minimal subluxation was corrected with optical correction "for partial support CTR ring,or rigid PMMA lens for minimal support or dislocation Lensectomy + vitrectomy + scleral fixated IOL was done

Coloboma cataract management: Slit-lamp examination of grade of cataract, microcornea, non-dilating pupils and zonular loss/phacodonesis.,presence of nystagmus and strabismus, amblyopia, colobomas retinal pathologies were also documented CTR rings were used to support lower bag,

Post trabeculectomy Cataract management: after Careful evaluation of glaucoma control temporal small incision manual cataract surgery or phacoemulsification was performed. For post vitrectomy cataract silicon oil removal combined with cataract surgery.

Secondary glaucoma management were treated according to cause,

Post operative management was done according to cause.

All patients were followed up according to standard format and schedule.

All pre operative scores divided in 3 categories $1-5,6-10$ and $>10$ which was studied comparing visual outcome. Prognosis was worsen from small to large.

All data were included in pre tested online format in EMR data exported in excel sheet and analysed using SPSS 22 with descriptive and cross tabulation function. All numerical variables tested by One sample T test.

\section{Results}

Our cohort was consisted of 230 eyes of 230 patients with mean age $44+/-21.22$ years with 121/230(52.6\%) female and 109/230(47.4\%) male. (Table-1) 
Considering clinical conditions Post trauma 64/230(27.8\%) followed by Corneal opacity 45/230(19.6\%) and Post uveitis 43/230(18.7\%) were most common conditions. (Table-2) When we studied outcome and compared other categories we found significant difference only in neglected category. (Table-3)

Out of all cases $37 / 230$ (16.1\%) were pediatric age group visual outcome was better in adult (Table-3)

On presentation 9/230(3.8\%) eyes had no perception vision while $157 / 230(68.3 \%$ ) had vision $<1 / 60$. In post-operative $5 / 230(2.2 \%)$ were having no perception and $74(32.2 \%)$ had vision $<1 / 60)$.

When we studied visual outcome with various clinical categories we found significant difference in neglected cataracts $(p=0.010)$ we have done comparative study pre and post-operative vision and found significant difference. $(p=0.037)$

\section{Discussion}

Over the last 2-3 decades, it has been proven that cataract surgery has been of immense benefit in visual rehabilitation of patients with uveitis and cataract. Cataract surgery with lens implantation has been established as a safe modality of treating cataract in pts with uveitis. $(9,10)$

Conventional cataract surgery for complicated cataract secondary to chronic uveitis is confronted with many complications, such as recurrent inflammation, pupillary membrane, glaucoma, etc. [11] This could be due to existing cystoid macular oedema as a part of the uveitic disease process, as has been reported by Diamond et al[12]. But it is hard to determine pre-existing findings before surgery in presence of the cataract. Diamond et all are of the opinion that mechanical removal and debridement of the vitreous framework in association with the lens, facilitates the elimination of the cellular material from the vitreous cavity i.e. large number of inflammatory cells in the vitreous cavity and the persistent immune complexes are mechanically reduced and contributes to the beneficial effect in such cases.

Bhargava et al reported small incision cataract surgery with lens implant is safe in post uveitic cataracts. (13)

Yi Hu Jo et al reported Phacoemulsification and IOL implantation in selected cases of coexisting cataracts and corneal opacities is safe that can provide suboptimal but long-term vision when penetrating keratoplasty is not possible or at high-risk of graft failure. ASOCT is a simple tool to predict visual outcomes after cataract surgery in opacified corneas (14)

Sinha et al reported Extracapsular cataract extraction and intraocular lens implantation with pupillary sphincterotomy provides ambulatory and useful vision to patients of cataract with coexisting central leucomatous corneal opacity (15)

Authors previous studies reported traumatic cataracts has optimum outcome if managed according to morphology and proper protocols in adult as well as pediatric population. $(16,17)$ 
Elanore et al and Olcker et al reported In patients with lens induced uveitis and phakolytic uveitis in the developing world where cataract surgery rates are lower, LIU rates are higher together with the associated complications. $(18,19)$

Azhany $Y$ et al reported outcome of neglected cataracts in Malaysia (20)

Joshi et al reported high incidence of primary capsular opacity and reduction in vision in rural population with neglected cataract. (21)

Agarekar et al reported Cataract surgery with IOL implantation in vasectomized eyes among children is a safe procedure and can improve visual acuity and quality of life (22)

Gopal et al reported Cataract surgery in these eyes can pose a challenge due to a combination of microphthalmos and relatively hard lenses, resulting in increased risk of intra-operative complications. (23)

Current study has reported collective visual outcome for all conditions for spectrum of multiple conditions resulting in significant improvement in vision and significant difference amongst different clinical conditions.

We are not aware about any study reported similar findings for all clinical conditions.

\section{Conclusion}

Complicated cataract with coexisting morbidities has significant improvement in vision after cataract surgeries with different techniques. Neglected cataracts has better visual outcome than other clinical conditions.

\section{References}

1. Lawani R, Pommier S, Roux L, Chazalon E, Meyer F. Magnitude and strategies of cataract management in the world. Med Trop (Mars) 2007; 67:644-50.

2. Brian G, Taylor H. Cataract blindness-challenges for the $21^{\text {st }}$ century. Bull World Health Organ 2001; 79:249-56.

3. Murthy G, Gupta SK, John N, Vashist P. Current status of cataract blindness and Vision 2020: The right to sight initiative in India. Indian J Ophthalmol 2008; 56:489-94.

4. Muhtaseb M, Kalhoro A, lonides A. A system for preoperative stratification of cataract patients according to risk of intraoperative complications: A prospective analysis of 1441 cases. $\mathrm{Br} \mathrm{J}$ Ophthalmol 2004; 88:1242-6

5. Chan E, Mahroo OA, Spalton DJ. Complications of cataract surgery. Clin Exp Optom 2010; 93:379-89 
6. Vinay Agrawal, Jinish Upadhyay and *Indian Cataract Risk Stratification Study group Validation of scoring system for preoperative stratification of intra-operative risks of complications during cataract surgery: Indian multi-centric study Indian J Ophthalmol: 2009;57:213-215

7. Shah MA, Shah SM, Shah SB, et al. Morphology of traumatic cataract: does it play a role in final visual outcome? BMJ Open 2011; 1: e000060. doi:10.1136/ bmjopen-2011-000060

8. Shah MA, Shah SM, Patel KD, Shah AH, Pandya JS. Maximizing the visual outcome in traumatic cataract cases: The value of a primary posterior capsulotomy and anterior vitrectomy. Indian $\mathrm{J}$ Ophthalmol 2014;62:1077-81

9. Satish Desai, Vinita Rao. "Visual Outcome after Cataract Surgery in Complicated Cataract". Journal of Evolution of Medical and Dental Sciences 2014; Vol. 3, Issue 34, August 11; Page: 9142-9156, DOI: 10.14260/jemds/2014/3180

10. Rupesh Agrawal,1 Somashiela Murthy, Sudha K. Ganesh, Chee Soon Phaik,Virender Sangwan,2 and Jyotimai Biswas3 Cataract Surgery in Uveitis International Journal of Inflammation Volume 2012, Article ID 548453, 16 pages doi:10.1155/2012/548453

11. Namperumalsamy P, Das T. Surgical treatment of complicated cataract following chronic uveitis. Indian J Ophthalmol [serial online]1982 [cited 2020 Sep 16 ];30:87-89

12. Diamond, J G. and Kaplan, H.J., 1978, Arch. Ophthalmol. 96: 1798.

13. Rahul Bhargava, Prachi Kumar,Hafsa BashirShivkumar Sharma and Anurag Mishra Manual sutureless small incision surgeries for uveitic cataracts Middle East Africa J ophthal;2014 JanMar:21(7) 77-82

14. Yi-Ju Ho1*, Chi-Chin Sun2,3* and Hung-Chi Chen 1 Cataract surgery in patients with corneal opacities BMC Ophthalmology (2018) 18:106

15. Rajesh Sinha, Namrata Sharma and Rasik B Vajpayee Visual outcome of cataract surgery with pupillary sphincterotomy in eyes with coexisting corneal opacity BMC Medicine 2004, 2

16. Shah SM, Shah MA, Singh R, Rathod C, Khanna R. A prospective cohort study on the epidemiology of ocular trauma associated with closed-globe injuries in pediatric age group. Indian J Ophthalmol. 2020;68(3):500-503. doi:10.4103/ijo.IJO_463_19

17. Mehul Ashvin Shah \& Shreya Mehul Shah \&Shashank B. Shah \& Chintan G. Patel \& Utsav A. Patel \& Adway Appleware \& Ashish Gupta Graefes Arch Clin Exp Ophthalmol (2011) 249:1775-1781

18. Eleanor Ngwe Nche1 \& Radgonde Amer1 Lens-induced uveitis: an update Graefe's Archive for Clinical and Experimental Ophthalmology https://doi.org/10.1007/s00417-019-04598-3

19. Olcker, H. E. and G. Naumann (1975). "[Clinical findings in phakolytic glaucoma (author's transl)]." Klin Monbl Augenheilkd166(5): 613-8.

20. Azhany Y, Hemalatha C, Nani D, Rosediani M, Liza-Sharmini AT Sequelae of neglected senile cataract Malaysian Family Physician2013;8(1):33-7

21. Rajesh Subhash Joshi Primary posterior capsular opacification in Indian rural population undergoing cataract surgery for hypermature senile cataract Clinical Ophthalmology 2013:7 1605-1608 
22. Agarkar S, Mailankody S, Settu S, Srinivasan R, Raman R. Visual outcomes following cataract surgery with intraocular lens implantation in vitrectomized eyes among children. Indian $\mathrm{J}$ Ophthalmol 2021;69:2078-81

23. Gopal Lingam ,Alok C. Sen, Vijaya Lingam, Muna Bhende, Tapas Ranjan Padhi, Su Xinyi1 Ocular coloboma-a comprehensive review for the clinician Eye (2021) 35:2086-2109

\section{Declarations}

- No financial support was received from any company or institution.

- This study has not been presented at any conference or meeting.

- The authors have no financial interest in any aspect of this study.

- Conflicting interests: None to declare.

- No financial support was received from any company or institution.

- This study has not been presented at any conference or meeting.

- The authors have no financial interest in any aspect of this study.

- Conflicting interests: None to declare.

\section{Tables}

Table-1 Age and sex distribution

\begin{tabular}{|clll|}
\hline Age categories & Sex & \multicolumn{2}{l}{ Total } \\
\cline { 2 - 3 } & Female & Male & \\
\hline $0-10$ & 17 & 9 & 26 \\
\hline $11-20$ & 8 & 6 & 14 \\
\hline $21-30$ & 8 & 16 & 24 \\
\hline $31-40$ & 11 & 19 & 30 \\
\hline $41-50$ & 13 & 20 & 33 \\
\hline $51-60$ & 25 & 18 & 43 \\
\hline $61-70$ & 26 & 19 & 45 \\
\hline$>70$ & 13 & 2 & 15 \\
\hline Total & 121 & 109 & 230 \\
\hline
\end{tabular}


Table-2 Clinical categories

\begin{tabular}{|lll|}
\hline Clinical Categories & Frequency & Percent \\
\hline Complicated Cloboma & 4 & 1.7 \\
\hline Corneal opacity & 45 & 19.6 \\
\hline Neglected & 39 & 16.9 \\
\hline Microphthalmos & 3 & 1.3 \\
\hline Other & 5 & 2.1 \\
\hline Post trabeculectomy & 9 & 3.9 \\
\hline Post Vitrectomy & 8 & 3.5 \\
\hline Subluxation & 10 & 4.3 \\
\hline Traumatic & 64 & 27.8 \\
\hline Post Uveitis & 43 & 18.7 \\
\hline Total & 230 & 100.0 \\
\hline
\end{tabular}

Table-3 Comparative study of visual outcome in different clinical condition

\begin{tabular}{|lll|}
\hline Clinical categories compared with other categories & P value & Remark \\
\hline Pediatric age group & 0.010 & Outcome poor in children \\
\hline Post traumatic & 0.272 & \\
\hline Post uveitis & 0.230 & \\
\hline Neglected & 0.015 & Outcome better in neglected \\
\hline Corneal opacity & 0.623 & \\
\hline Subluxated/Dislocated & 0.825 & \\
\hline
\end{tabular}

